\title{
TIME AND LOAD INDEPENDENT PROPERTIES OF BITUMINOUS MIXTURES
}

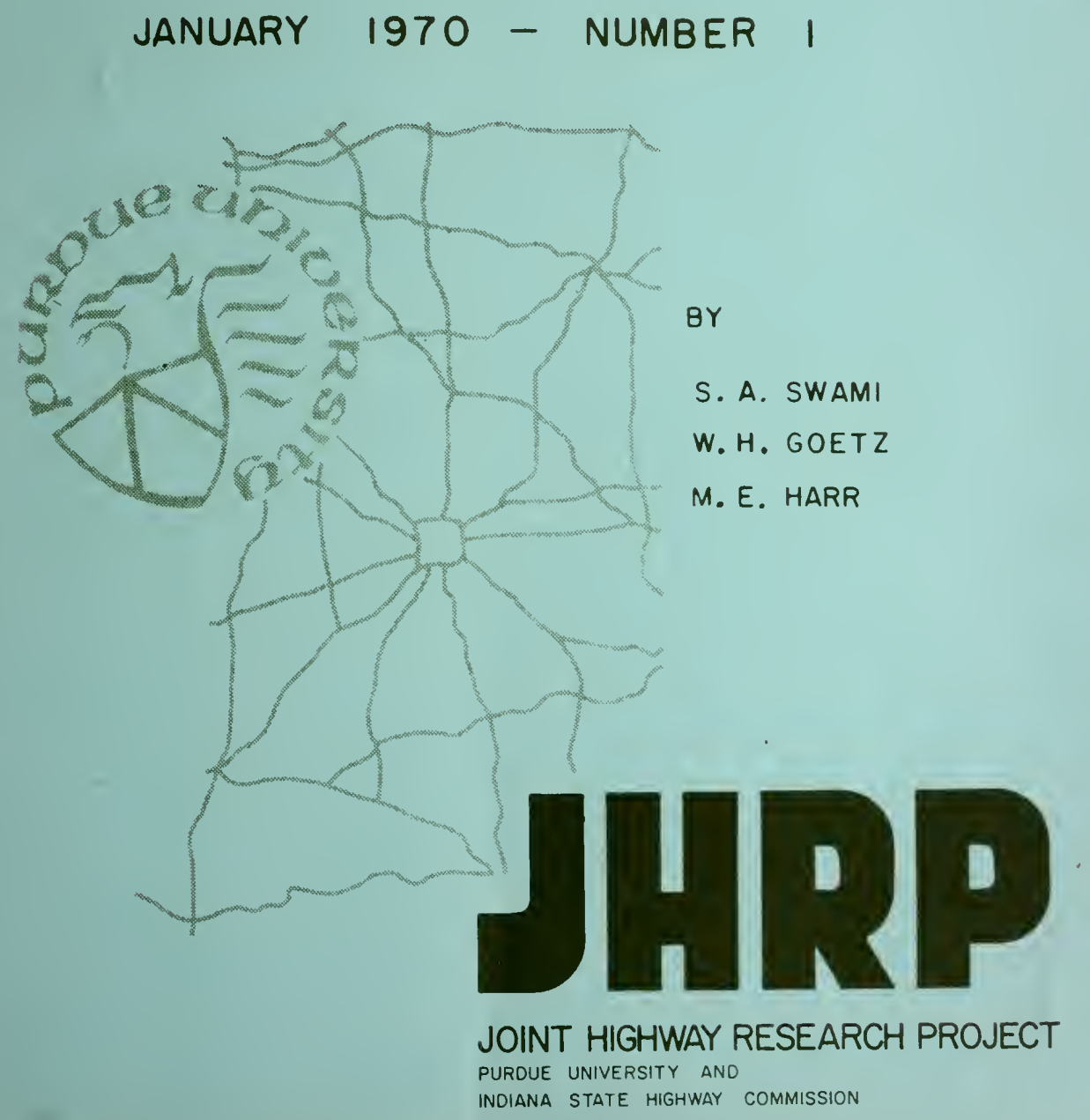


Digitized by the Internet Archive in 2011 with funding from

LYRASIS members and Sloan Foundation; Indiana Department of Transportation 
Technical laper

TIME AND LOAD INDEPENDENT P'ROL'TR'TIES OF BITUMINOUS MIXTURES

by

S. A. Swami

Associate Professor of Civil Engineering

West Virginia Institute of Technology - formerly

Graduate Assistant, Purdue University

i. H. Goetz

Professor of Highway Engineering

Purdue University

M. E. Harr

Professor of Soil Mechanics

Purdue University

Prepared as Part of an Investigation

Conducted by

Joint Highway Research Project

Engineering Experiment Station

Purdue University

in cooperation with the

Indiana State Highway Commission

and the

U. S. Department of Transportation

Federal Highway Administration

Bureau of Public Roads

The opinions, findings and conclusions expressed in this publication are those of the authors and not necessarily those of the Burcau of Public Roads.

Not Released for Publication

Subject to Change
For presentation at the Annual Meeting of the Highway Research Board, January 13-17 1970

Purdue University

Lafayette, Indiana

January 1970 


\section{SYNOPSIS}

This paper presents a new approach to characterize the time-dependent behavior of asphaltic concrete by a transfer function which is derived from the frequency response of the material, using sinusoidal loading tests. The ratio of the Laplace transform of the output to the Laplace transform of the input to any system is defined as the transfer function of the system between the input and the output. The transfer function is a function of the complex variable $s=j \omega$, where $\omega$ is the frequency of the pinput and $j$ is the imaginary unit.

In this study asphaltic concrete was treated as a damped, linear system in which the applied force $f(t)$ was the input and the resulting displacement $x(t)$ was the output. Both the input and output were functions of time. By varying the frequency of the input the output-input magnitude ratio was obtained for each frequency and its plot against log frequency yielded the frequency spectrum. Also, the time lag between the output and the input was noted from which the phase angle was calculated.

A simple geometric technique to obtain the transfer function directly from the frequency spectrum was used in this investigation. This technique was applied to the results of the test specimens of asphaltic concrete cut from laboratory compacted beams of two different compositions tested at three temperatures. It is shown that the transfer function for bituminous concrete thus derived from a dynamic test can be used to predict the displacement of the test specimen subjected to a static load by treating the latter as a step function of time and through the use of Laplace inverse transform. The excellent agreement between the calculated and measured values of the displacements indicates that the transfer function represents a material property which is independent of load input. 
The concept of transfer function makes it possible to represent the timedependent behavior of asphaltic concrete by a fourth order linear differential equation with constant coefficients without assuming any spring-dashpot model. The coefficients can be computed from the roots of the denominator and numerator of the transfer function.

\section{INTRODUCTION}

Theoretical developments in the stress-displacement behavior of asphaltic concrete in a pavement structure are very restricted in their applicability to represent actual field conditions due to the complexity of asphaltic concrete as a structural material and the complicated interaction with the other structural layers. A rigorous theoretical solution to a typical boundary value problem in pavement mechanics must satisfy the equations of equilibrium (or motion), compatibility equations (or some other form of conservation equation), boundary conditions, and initial conditions. The development of such a solution requires the use of some form of stressdisplacement-time relation for the material, and it is this aspect which specifies the solution for a particular medium. At present, there are no satisfactory constitutive relations available for pavement materials, both asphaltic concrete and soils, and this is perhaps the greatest impediment to realistic theoretical solutions of the response of pavement systems to applied loads, dynamic or static.

Having the ultimate objective to design such layered pavement structures, the theory of 1 inear viscoelasticity has been widely used for the evaluation of pavement components as well as for understanding their response to varied loading conditions. Layered systems were not, however, analyzed using timedependent (viscoelastic) material properties until after the development of the correspondence principle for isotropic media in 1955 by Lee (1)* and shortly 
thereafter the extension by Bict (2) to include atisotropic media. Stress and strain for linear viscoelastic materials can be related by 6 ither differential or integral linear operators. The differential operator form of the stress-strain law is most commonly used and as Biot (3) has pointed out may be visualized as a combination of springs and dashpots. More general methods of viscoelastic stress analysis have been described by Lee (4) and Lee and Rogers (5).

Pister and Monismith (6) have applied the basic differential equation for the three element model to the solution of a viscoelastic beam on an elastic foundation. Pister $(7)$ has considered the solution of a viscoelastic plate on a viscoelastic foundation. Other literature $(8,9,10)$ also exist in limited quantity dealing with viscoelastic slabs or fourdaticns in various ways. Harr (11) used a two element model to show the influence of vehicie speed on pavement deflection. The usefulness of these methods is zestricted to the extent of the realistic representation of the viscoelastic characteristics of the materials of the pavement structure in the numerical analysis.

The study of viscoelastic characteristics of bituminous mixtures has been the object of many research workers, and here again spring-dashpot models have been generally made use of. By using a Burger's model, Wood and Goetz (12) found that the behavior of a sheet asphalt mixture obeyed the laws of linear viscoelasticity for limited stresses and small deformations. Secor and Monismith (13) observed that the four element model, suggested by Kuhn and Rigden (14) was capable of representing the displacement of an asphaltic concrete only to a limited extent.

Dynamic tests, such as those employing sinusoidal loading, have been used to study the viscoelastic response of asphaltic concrete by some investigators $(15,16,17)$. They have attempted to characterize the viscoelastic response by using the phase angle and the complex elastic modulus, obtaired 
from the input-output traces of the dynamic tests. However, these parameters are not easily adaptable for numerical analysis. Besides, they are functions of the input 1oad, which seriously limits the ability of these parameters to truly represent the load response characteristics of the material.

This motivated the authors to search for a parameter or parameters or a function which can represent the viscoelastic response of the material under any load and which, at the same time, is independent of the type and magnitude of the input load. Such a function should necessarily be time-dependent and should be used as the material characteristic for both static and dynamic loads. A study of the literature reveals that transfer functions are frequently used to characterize a dynamic system in electrical and mechanical engineering problems ( 18 through 23). While serving as a link between the time-dependent input and output of the system, the transfer function completely describes its dynamic response. Hence, it was attempted to investigate the feasibility of applying the concept of transfer functions to describe the response of bituminous mixtures to dynamic and static loads. This paper presents a method of obtaining the transfer function for a given bituminous concrete from laboratory tests and studies the extent to which this function can represent the viscoelastic characteristics of the material. Effects of mix type, temperature and anisotropy on the transfer function were studied with a view to providing insight into this function which, it is hoped, may facilitate the development of more refined methods for the structural design of pavements.

It is assumed in this investigation that asphaltic concrete behaves as a linear system. Although it has been recognized that the behavior of this material is nonlinear particularly at higher stress levels and at higher temperatures, the investigations of Busching, Goetz and Harr (24), and others $(15,25)$ have established the validity of this assumption for small displacements normally encountered in bituminous mixtures. 


\section{CONCEPT OF TRANSEER FUNCIION}

The ratio of an operational cutput (Laplace transform of the output) of a dynamical system to the operational input (Iaplace transform of the input) is calied the transfer function between the operational input and its corresponding output. The transfer function is shown schematically in Fig. 1. It is by definition a function of the complex variable $s$.

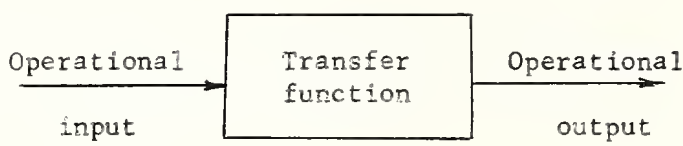

Fig. 1. Block diagram representation of the transfer function.

If a rigid body is subjected to a dynamical force $f(t)$, then the force and the resulting displacement $x(t)$ can be considered as the input and out o put respectively for the dynamic system. The transfer function between the operational force and the operational displacement is given by

$$
G(s)=\frac{x(s)}{\dot{x}(s)}
$$

Where $G(s)$ w the transfer function

$$
\begin{aligned}
& \bar{x}(s)=\text { Laplace transform of the output, } \ell\{x(t)\} \\
& \bar{f}(s)=\text { Laplace transform of the input, } \ell\{f(t)\} .
\end{aligned}
$$

Solving for $\dot{x}(s)$,

$$
\vec{x}(s)=G(s) \pm(s)
$$

The inverse transform of $\bar{x}(s)$ is $x(t)$ and is

$$
x(t)=e^{-1}\{G(s) \bar{f}(s)\}
$$


Eq. 3 shows that once the transfer function $G(s)$ is known for any system, the displacement $x(t)$ can be evaluated for that system for another given input force $f(t)$.

In general, the transfer function $G(s)$ is a ratio of two polynomials in $s$, such as

$$
G(s)=\frac{N(s)}{D(s)}=\frac{\left(s-a_{1}\right)\left(s-a_{2}\right) \cdots\left(s-a_{n}\right)}{\left(s-b_{1}\right)\left(s-b_{2}\right) \cdots\left(s-b_{m}\right)}
$$

where $a_{i}$ 's and $b_{i}$ 's are the roots or zeros of the numerator $N(s)$ and denominator $D(s)$ of $G(s)$ respectively. $b_{i}$ 's are also called the poles of $G(s)$, since the transfer function becomes infinite when evaluated at a zero of its denominator. That is,

$$
G\left(b_{i}\right)=\infty
$$

Substituting for $\mathrm{G}(\mathrm{s})$ in $\mathrm{Eq} \cdot 2, \overline{\mathrm{x}}(\mathrm{s})$ can be rewritten as

$$
\bar{x}(s)=\frac{\bar{f}(s)\left(s-a_{1}\right)\left(s-a_{2}\right) \cdots\left(s-a_{n}\right)}{\left(s-b_{1}\right)\left(s-b_{2}\right) \cdots\left(s-b_{m}\right)}
$$

Eq. 6 can be expanded in $m$ partial fractions for the $m$ roots of $D(s)$ as

$$
\bar{x}(s)=\frac{c_{1}}{\left(s-b_{1}\right)}+\frac{c_{2}}{\left(s-b_{2}\right)}+\cdots+\frac{c_{m}}{\left(s-b_{m}\right)}
$$

which is an identity in $s$ where $c_{1}, c_{2}, \ldots, c_{m}$ are constants independent of $s$. Using the Laplace inverse transform, the final solution for $x(t)$ is obtained from Eq. 7 as

$$
x(t)=c_{1} e^{b_{1} t}+c_{2} e^{b_{2} t}+\cdots+c_{m} e^{b_{m} t}
$$

From the above discussion it is obvious that once the transfer function for a system is known, the displacement $x(t)$ of the system for a given force 
input $f(t)$ can be evaluated theoreticaliy.

\section{DETERMINATION OF IHE TRANSEER FUNCTION}

The experimental basis to determine the transfer function for a test specimen is the frequency spectrum, which, in turn, may be obtainet from sinusoidal input-output data of the test specimen (23). The plot of the amplification (that is, the ratio of the output magnitude to the input magnitude against the test frequency is the frequency spectrum, and for convenience the magnitude of the amplification is plotted in decibels\%. The frequency spectrum is approximated with a series of connected straight lines so as to form asymptotes to the curve, see Fig. 2 . The intersections of the asymptotes determine the corner irequencies. The modified transfer function is then obtained (26) as a function of the slopes of the asymptotes and their corner frequencies as

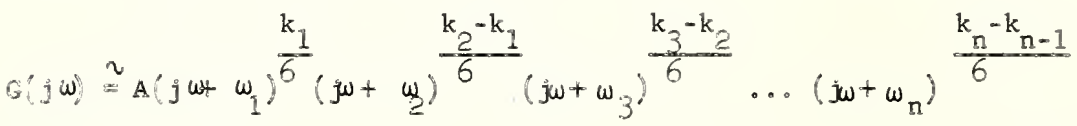

The modified transfer function is the vector amplification or simply the ratio of the magnitude of the output to that of the input and is a function of the input frequency. By substituting $s=j$ win Eq. 9, the transer function for the system is obtaired

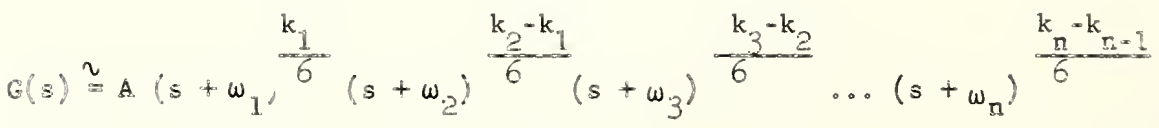

The constant A can easily be determined from any one experimental frequency in the frequency spectrum by calculating the absolute value of the transfer furction from Eq. 9 at that frequency and eguating it to the corresponding amplification value in the frequency spectrum.

$R_{d b}=20 \log _{10} R$ 


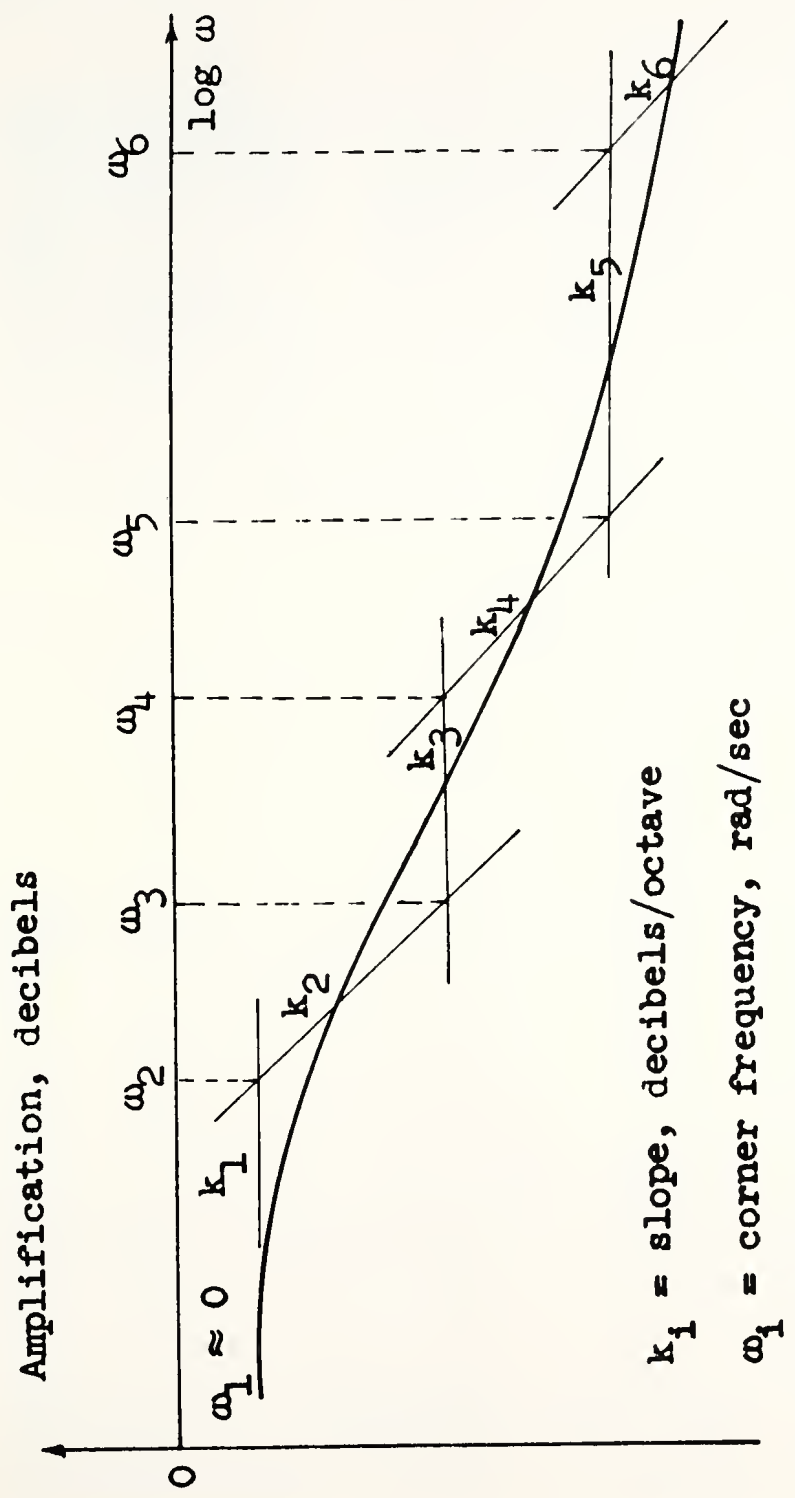


In approximating the frequency spectrum, the slopes of the asymptotes Qte generaliy taken to be six decibels per octave* for greater ease of determination, although straight lines of any slope may be used. The closer the approximation to the actual frequency spectrum curve, the better will be the approximation of the transfer function being sought.

\section{EXPERTMENAL INVESIIGAIION}

The experimental phase of this study had as an objective the development and use of accurate techniques for obtaining all of the data required in the determination of the transfer function from a frequency spectrum. Whe core of the technique lies in devising a system which can apply a simualdal force input of a desired magnitude and frequency and which can simultaneously measure the displacement output.

An MIS Electronic function generator ccupled with a loading frame which Was fitted with an electronically controlled hydraulic actuator was used for this pitpose. See Figs. 3 and 4 . The loading frame was installed in a constant temperature room which facilitated carrying out the tests at the desired temperatures. A two-channel Brush recorder which was attached to the function generator recorded the input and output of the test specimen simultaneousiy.

\section{Dynamic Tests}

The function generator was used to apply sinuscidal force inputs to the asphaltic concrete specimen by suitable manipulation of the controls. The magnitudes of the force varied from 2.5 to $15 \mathrm{lbs}$. and the frequercies varied from 0.0016 to 1.6 cycles per second.

* An cctave is defired as the frequency range for which the ratio of the upper hamd frequency to the lower bourd frequency is 2 to 1 ; that is, $w_{i}<w^{2} 2 w_{i}$ is an octave. 


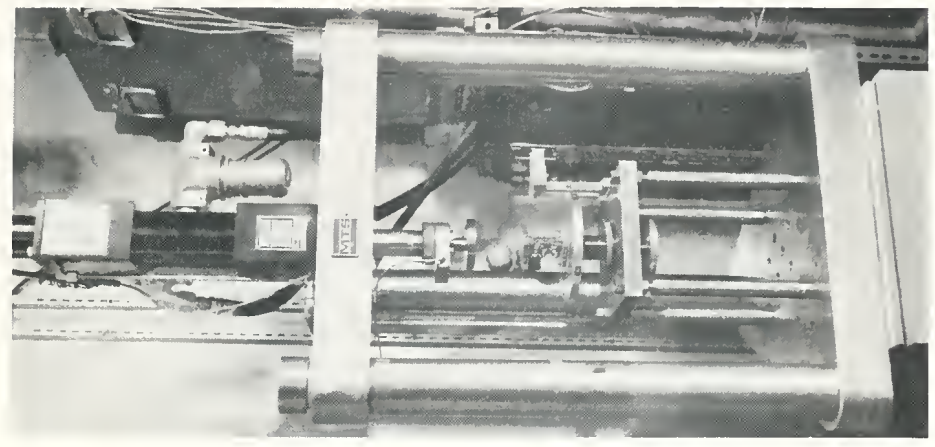

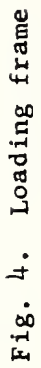

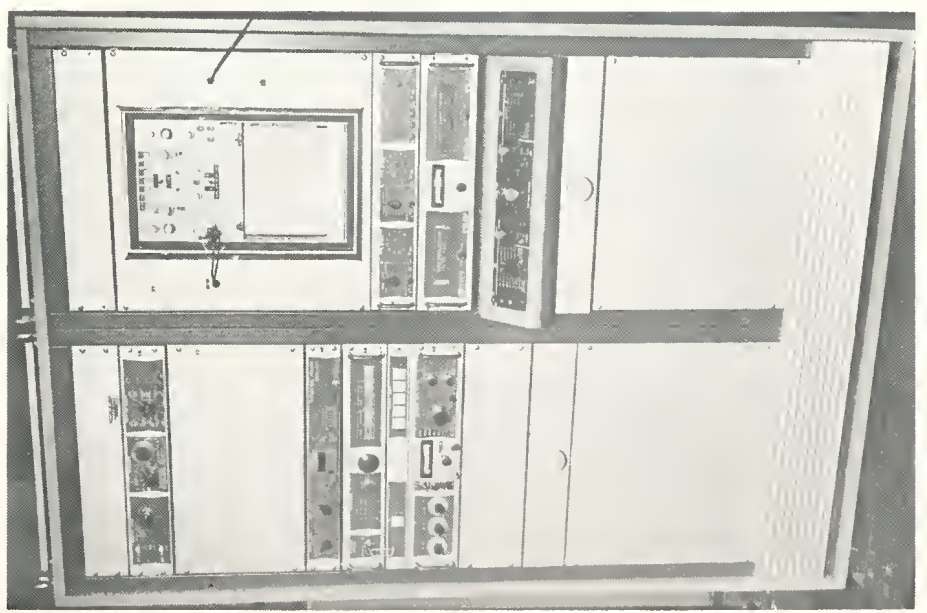

㟔 
Since in a sire test the specimen is alcernatively in compresston and In tersion, the method of mounting the specimen in the test assembly was of paramount importance. Two aluminum flates, 2 in。 $x 2$ in. $x 3 / 8$ in. in size, were glued to the specimer top and bottom respectively, using commercially available Eastman 910 Adhesive. The plates, in turn, were contected to the top and bottom platers by screws and rits. Ihe rop platen was rigidly fixed to the moving ram of the hydraulic actuator while the bottom platen was fixed to the loading deck. SeE Fig.5. Remotely controiled and commanded by the electronic consols of the function generator, the hydraulic cam moves up and down at the pre-set sine force and frequency. Thus the specimen waz subjected to the desired sidusoidal force input which was wecorded by the left channel of the Brush recowder. The corresponding displacement of the specimen was sunged by the IVDI in the actuator and wes simuitaneously recorded as the output frit the right channel of the recorder. Eig. 6 shows the two traces thus obtained in a typical dyaamic test.

\section{Static iests}

The same test assembly which was ysed for the dynamic tests was ubed for the static tests. When the furction genertor is set for a combiraticn of a tamp function and a high fruquency, the astuator applies a stutic corgressty forco of desired magr cherrels recorded the input and output respectively. The two tasces of $a$ typical statis compession test are illastated in Fig. ?

\section{Materials and Dreparations of Specimess}

Two different gradings, one with a maximum size of the No. 4 sieve and the other the $3 / 8$ inch sieve were user in this investigarion. The bituminous mixes propared on the basis of these gradings were designated as Mix-1 and Mix-2, respectively. A $60-70$ peretration asphalt cement was used. The mix was compacted into beams of size 2 in. $x 21$ in in. $x 12$ in. from which test 


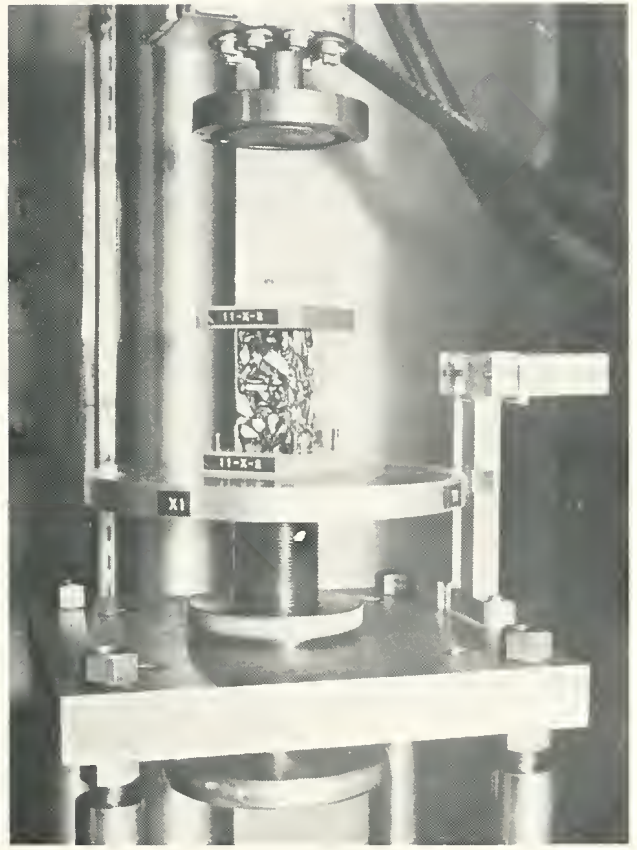

Fig. 5. Specimen in position for testing 


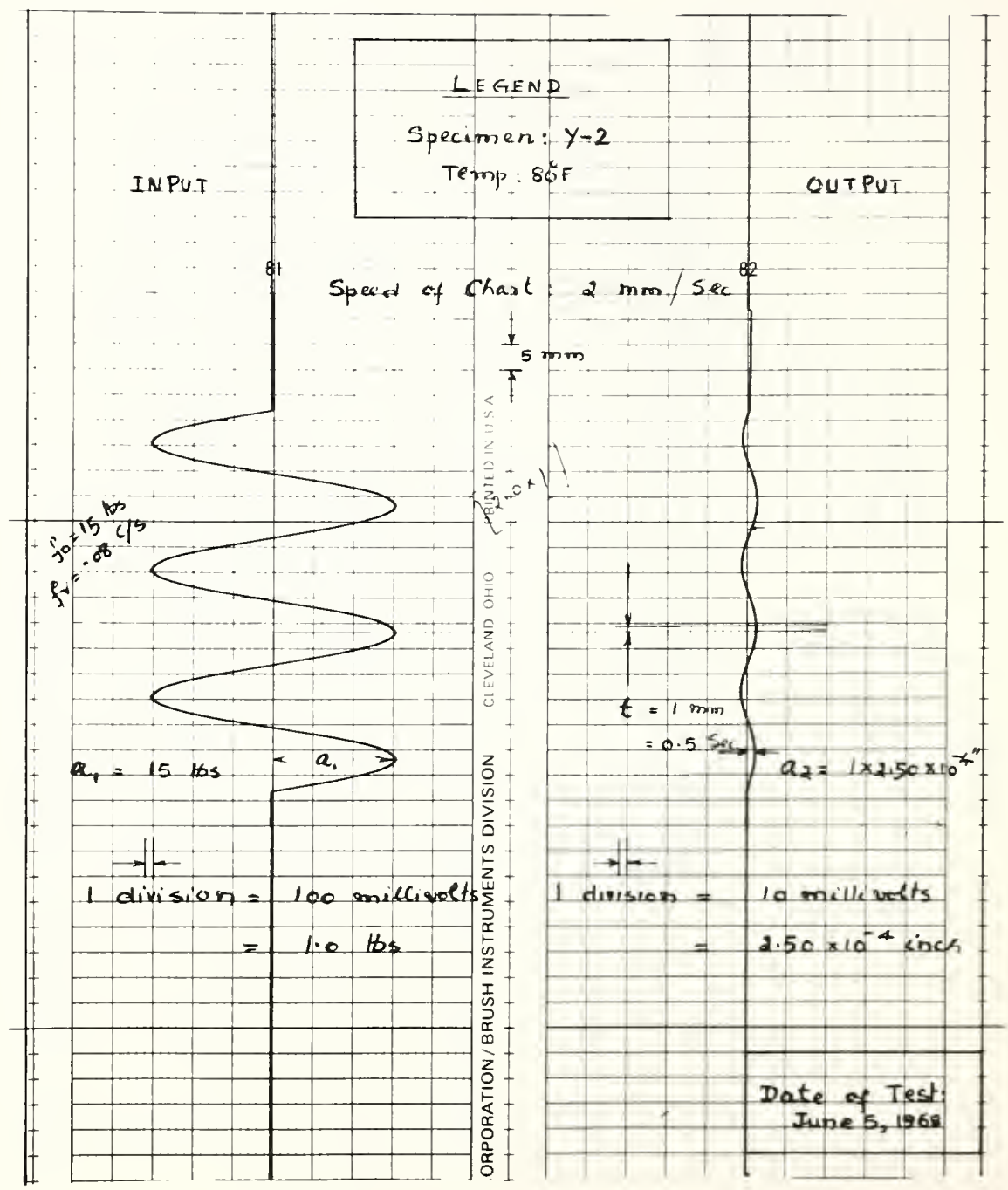

Fig. 6. Typical traces of a sinusoidal loading test 


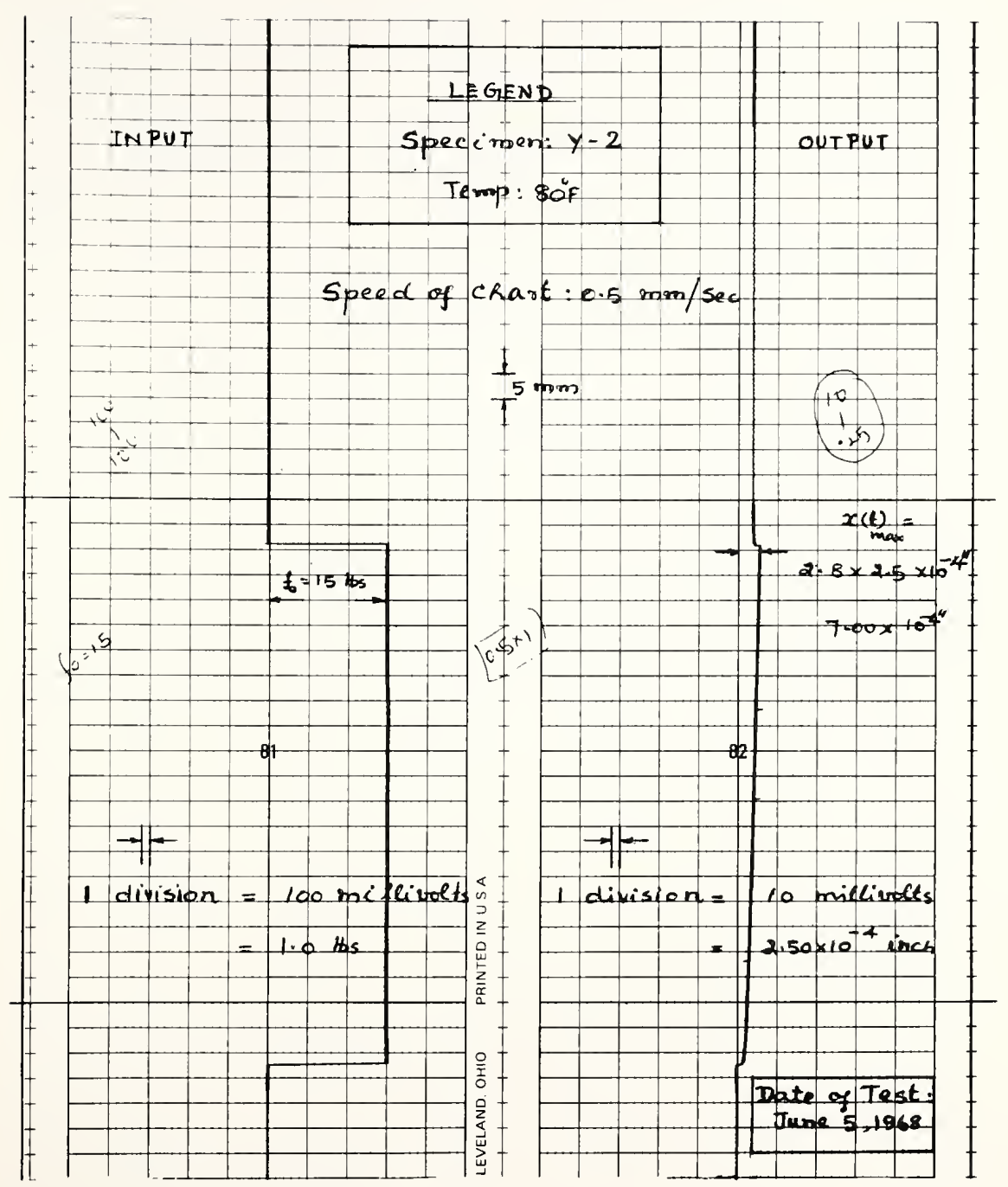

Fig. 7. Typical traces of a static compression test 
specimens of dimensions 1 in. $x 1$ in. $x .2$ in. were cut along the $x, y$ and $z$ axes of the beam, $x$ teing the longss: jxis and $z$ the vertical dxis. The specimens wera designated as $X-1, Y-1, Z-1, X-2, Y-2$ and $2-2$, the $1 \in t$ ter denoting the axis along which it was cut and the numeral the mix. The details of obraining the specimens are shown in Reference 26.

\section{DISCUSSION OF RESULTS}

\section{Frequency Response of Asphaltic Concrete}

In most of the dynamic tests a magnitude of 10 lbs. was employed for the sinusoidal load input for frequencies covering three decades, varying from 0.01 radiass per second to 10.0 radians per second. These were obseryed to be, respectively, the slowest and the fastest frequencies to which the test specimens were responsive. The input magnitude and the output disolacement were recorded in pounds and inches, respectively. Also, both of them were recorded in millivolts.

The ratio of the output to the input expressed in decibels (also referred to as amplification or gain) plotted against log frequency gives the desired frequency spectrum. The phase lag or simply the phase angle for each frequency was also computed from

$$
\phi=\omega t
$$

where $\emptyset=$ the phase angle in radians

$\omega=$ the test frequency in rad/sec, and

$t=$ time lag between input and output in seconds.

The phase angie is also plotted against log frequency. The two plots together represent the frequency response of the test specimen completely.

Table 1 shows typical test results for a dynamic test and Fig. 8 gives the frequency response for the same test. It is seen that the displacement of the specimen is largest at the slowest frequency and is least at the 


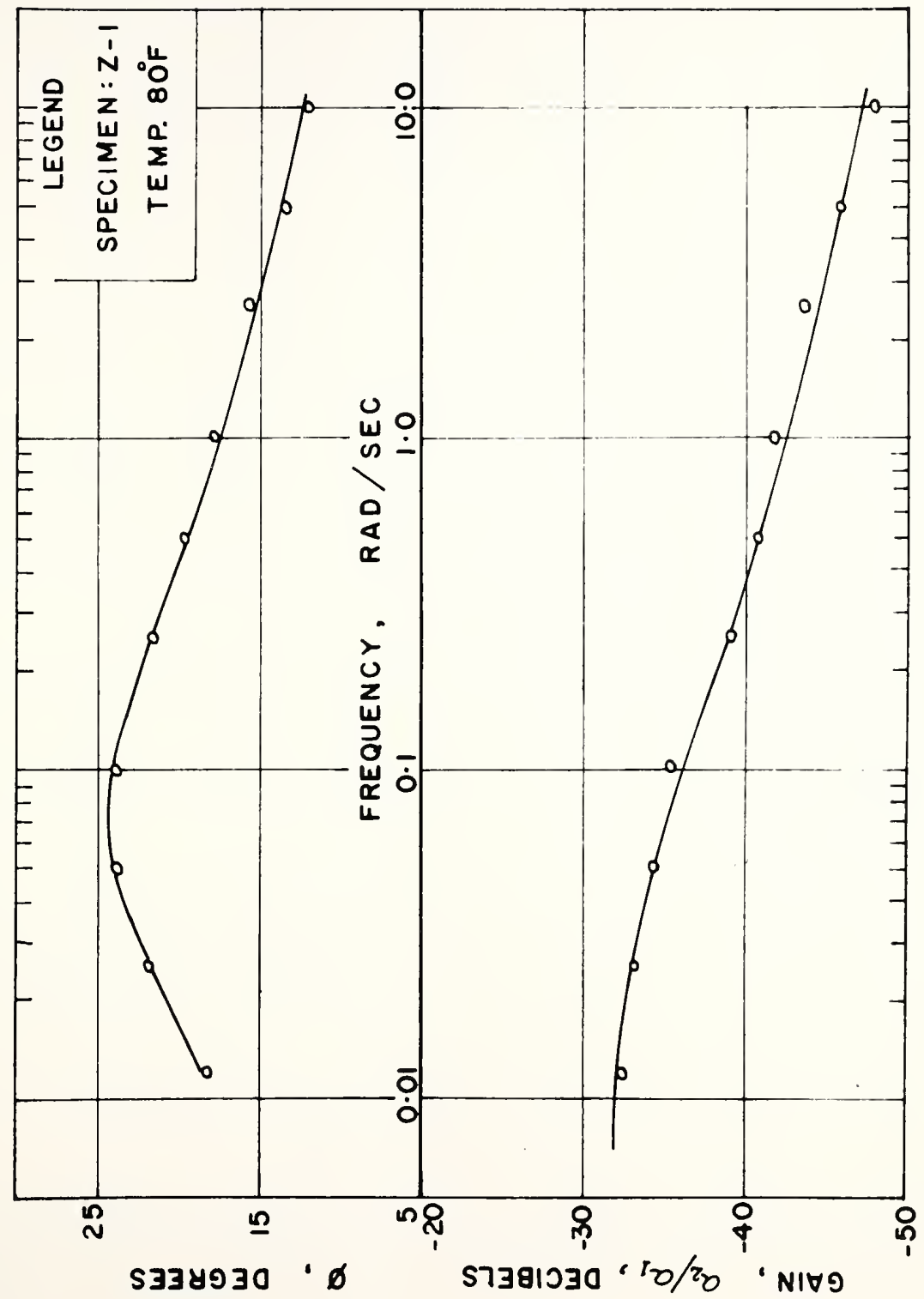

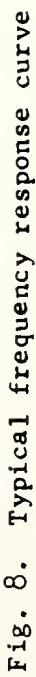


TABLE 1

Results of A Typical Sinusoidal Test

Specimen: $\quad z=1$

Test Temperature: $80^{\circ} \mathrm{F}$

\begin{tabular}{|c|c|c|c|c|c|c|c|}
\hline $\begin{array}{c}\omega \\
\mathrm{rad} / \mathrm{sec}\end{array}$ & $\begin{array}{l}a_{1} \\
\mathrm{mv}\end{array}$ & $\begin{array}{l}a_{2} \\
m v\end{array}$ & $\mathrm{R}=\frac{\mathrm{a}_{2}}{a_{1}}$ & $\mathrm{R}_{\mathrm{db}}$ & $\underset{s \in c}{t}$ & rad & deg. \\
\hline $\begin{array}{l}0.025 \\
0.050\end{array}$ & $\begin{array}{c}1000 \\
" 1\end{array}$ & $\begin{array}{l}22.0 \\
19.5\end{array}$ & $\begin{array}{l}0.0220 \\
0.0135\end{array}$ & $\begin{array}{l}-33.1520 \\
-34.4240\end{array}$ & $\begin{array}{r}15.30 \\
8.32\end{array}$ & $\begin{array}{l}0.382 \\
0.416\end{array}$ & $\begin{array}{l}21.8 \\
23.9\end{array}$ \\
\hline $\begin{array}{l}0.100 \\
0.250 \\
0.500\end{array}$ & $\begin{array}{l}" 1 \\
" 1\end{array}$ & $\begin{array}{r}17.0 \\
11.0 \\
9.0\end{array}$ & $\begin{array}{l}0.0170 \\
0.0110 \\
0.0090\end{array}$ & $\begin{array}{l}-35.3920 \\
-39.1720 \\
-40.9160\end{array}$ & $\begin{array}{l}4.15 \\
1.50 \\
0.68\end{array}$ & $\begin{array}{l}0.415 \\
0.375 \\
0.340\end{array}$ & $\begin{array}{l}23.8 \\
21.5 \\
19.5\end{array}$ \\
\hline $\begin{array}{l}1.000 \\
2.500 \\
5.000\end{array}$ & $\begin{array}{l}" 1 \\
" 1\end{array}$ & $\begin{array}{l}8.0 \\
6.5 \\
5.0\end{array}$ & $\begin{array}{l}0.0080 \\
0.0065 \\
0.0050\end{array}$ & $\begin{array}{l}-41.9380 \\
-43.7420 \\
-46.0200\end{array}$ & $\begin{array}{l}0.311 \\
0.110 \\
0.046\end{array}$ & $\begin{array}{l}0.311 \\
0.271 \\
0.230\end{array}$ & $\begin{array}{l}17.8 \\
15.5 \\
13.2\end{array}$ \\
\hline 10.000 & $"$ & 4.0 & 0.0040 & -47.9580 & 0.021 & 0.210 & 12.0 \\
\hline
\end{tabular}

LEGEND

$\omega=$ input irequency, rad/sec

$a_{1}=$ input magnitude, millivolts

$a_{2}=$ output magnitude, millivoits

$R:=a_{2} / a_{1}$

$R_{d b}=R$ expressed in decibels

$=20 \log _{10} \mathrm{R}$

$t=t$ ime lag between input and output, sec.

$\emptyset=$ phase lag between input and output

$=\omega t$ radians. 
fastest frequency. Thus the gain continuously falls with increase in frequency which indicates the overdamped nature of the test specimen.

The phase angle increases with increase in frequency in the first decade of test and then decreases so that a bell-shaped curve results when phase angle is plotted against frequency. The peak has, in general, been observed to occur in the region of 0.05 to $0.1 \mathrm{rad} / \mathrm{sec}$. These results substantiate the observations of Pagen and others who have studied the dynamic response of bituminous concrete in sinusoidal testing (15, 16, 17).

\section{Form of the Transfer Function}

Table 2 shows a set of typical transfer functions obtained for the specimens tested at $80 \mathrm{~F}$, from which it is seen that the transfer function derived for each individual case is of the form

$$
G(s)=\frac{A\left(s+a_{1}\right)\left(s+a_{2}\right)\left(s+a_{3}\right)}{\left(s+b_{1}\right)\left(s+b_{2}\right)\left(s+b_{3}\right)\left(s+b_{4}\right)}
$$

where $A$ is a constant and $a_{i}$ 's and $b_{i}$ 's are the corner frequencies as previously defined and which are obtained in the process of approximating the frequency spectrum with asymptotes. The significant feature of this form of the transfer function is that the factors in both the numerator and denominator are to first power. It may be recalled that this is due to the geometric procedure followed in approximating the frequency spectrum with asymptotes of slopes of six decibels per octave. It was also mentioned that any slope can be used, in which case it is obvious from Eq. 10 that the transfer function may contain fraction powered or higher powered terms in either the numerator or the denominator or both. This form is not desirable since the resulting transfer function will be too difficult or even impossible to handle through Laplace transforms.

From the procedure followed in approximating the frequency spectrum with asymptotes it is obvious that the number of factors in the numerator 
TABLE 2

Transfer Functions at $80^{\circ} \mathrm{F}$

Specimen

Transfer Function

$z-1$

$G(s)=\frac{(0.05)(s+0.025)(s+0.2)(s+2)}{(s+0.02)(s+0.1)(s+1)(s+10)}$

$x-1$

$G(s)=\frac{(0.0415)(s+0.028)(s+0.17)(s+1.8)}{(s+0.02)(s+0.1)(s+1)(s+10)}$

$y-1$

$G(s)=\frac{(0.04)(s+0.025)(s+0.16)(s+2.3)}{(s+0.02)(s+0.1)(s+1)(s+10)}$

$z-2$

$G(s)=\frac{(0.04)(s+0.025)(s+0.16)(s+2.3)}{(s+0.02)(s+0.1)(s+1)(s+10)}$

$x-2$

$G(s)=\frac{(0.0415)(s+0.028)(s+0.17)(s+1.8)}{(s+0.02)(s+0.1)(s+1)(s+10)}$

$y-2$

$$
G(s)=\frac{(0.0415)(s+0.028)(s+0.17)(s+1.8)}{(s+0.02)(s+0.1)(s+1)(s+10)}
$$


and denominator of the transfer function in Eq. 12 depends on the number of asymptotes used to approximate the frequency spectrum. It was found from the analysis of the experimental results that the transfer function obtained using eight asymptotes was accurate enough for practical purposes.

\section{Effect of Mix Type on Transfer Function}

The two different bituminous mixes studied in this investigation were quite dissimilar in their aggregate gradings and in their binder contents, name $1 \mathrm{y}, 5.0 \%$ and $3.5 \%$ by weight of aggregate for $\mathrm{Mix}-1$ and $\mathrm{Mix}-2$, respectively. However, it is apparent from Fig. 9 that there was no appreciable difference in the transfer functions of the specimens, irrespective of their composition or orientation when tested at any one temperature. Even though the grading and asphalt content were different for the two mixes, their density-void ratio characteristics were similar, name $1 \mathrm{y}, 142.6 \mathrm{pcf}$ and $6.5 \%$ for $\mathrm{Mix}-1$ and 142.0 pcf and $8.5 \%$ for Mix-2.

It can be anticipated that density will have a marked influence on the response to loading of a given mix and hence on its transfer function. However, more work is necessary to study the effect of this and other mix variables.

\section{Effect of Specimen Orientation}

It was pointed out under "Experimental Investigation", that for each mix three specimens were cut along three mutual perpendicular directions, designated $x, y$ and $z$. It is seen from Fig. 9 that there is not much difference in the transfer functions of the differently oriented specimens of either mix at any one temperature. This suggests that effect of anisotropy, if any, is not reflected in the transfer function.

\section{Effect of Temperature}

The experiments in the present investigation were conducted at 70 , 80 and 90F. By examining the absolute value curves in Fig. 9, it is 


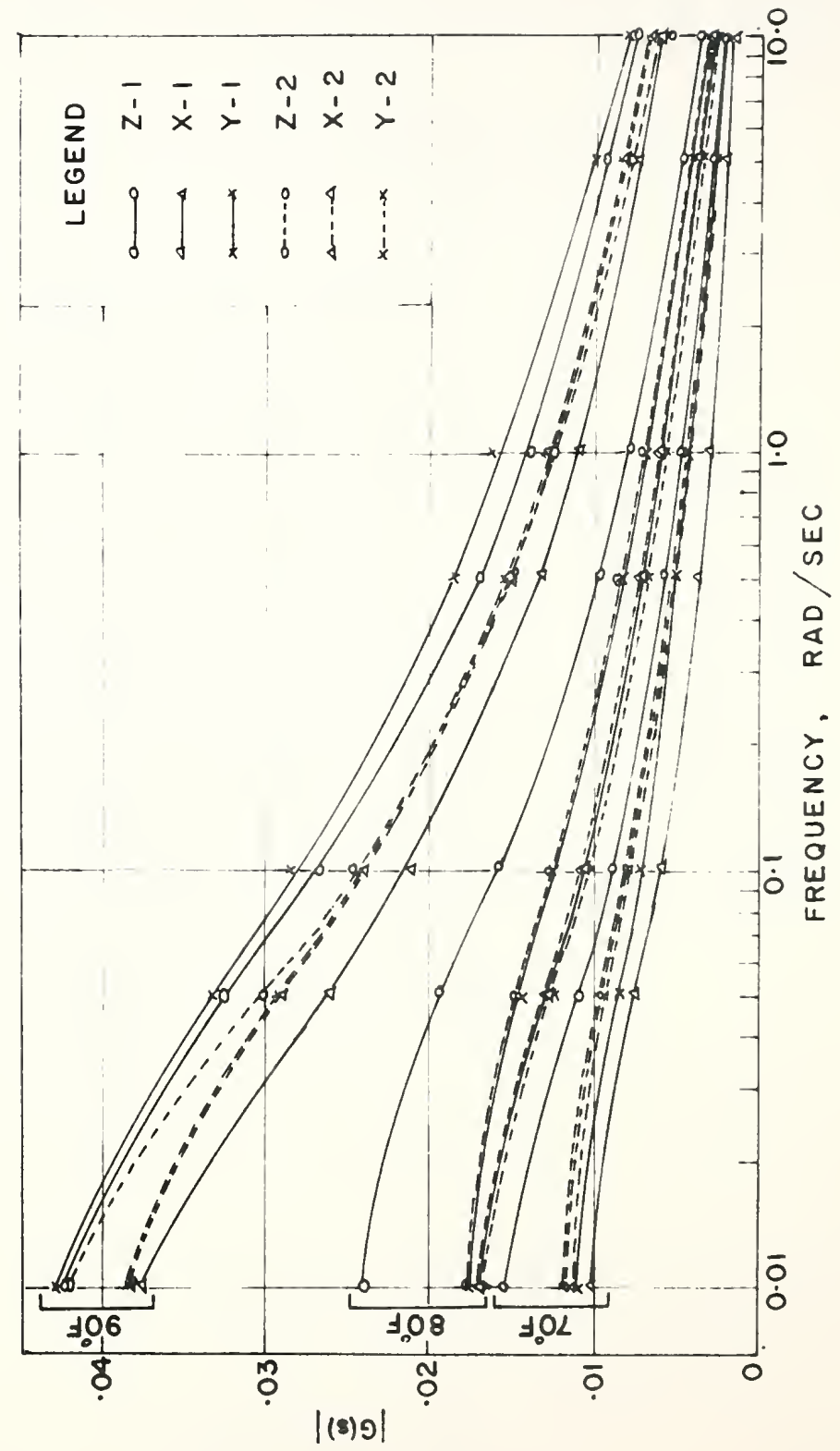

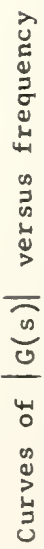
a $\underset{\substack{\infty \\ 1}}{\infty}$ 
readily seen that temperature plays an important role in the transfer function of any specimen. Asphalt cement being thermoplastic, the asphaltic concrete specimen will yield increased displacements for increases in temperature at a given stress level. This results in a decrease in viscosity of the binder in the asphaltic concrete as temperature increases. Thus the output-input ratio for a constant input at any frequency will increase with decrease in viscosity, or increase in temperature. This is precisely what is shown by the curves.

Examination of the transfer functions revealed that, for a given specimen, the various factors in the numerator and denominator do not seem to vary much with change in temperature, but that the coefficient A varies appreciably. It would be of interest to study this change in A with reference to the viscosity of asphalt cement or the asphalt cementfiller matrix.

\section{Effect of Specimen Size on Transfer Function}

Frequency-response tests were conducted on three different-sized specimens with constant height-width ratio using Mix-1 at 90F. They were cut along the same direction in the compacted beam. The large, medium and small sizes were $11 / 4^{\prime \prime} \times 1$ 1/4" $\times 21 / 2^{\prime \prime}, 1^{\prime \prime} \times 1^{\prime \prime} \times 2^{\prime \prime}$ and $3 / 4^{\prime \prime} \times$ $3 / 4^{\prime \prime} \times 11 / 2^{\prime \prime}$, respectively. Analysis of their test results showed that the frequency spectrums for the three specimens are nearly the same and that they can be approximated by one single transfer function, which shows that the transfer function for the $\operatorname{mix}$ is independent of the specimen size.

In the light of this observation, it appears that the transfer function can be used to represent the dynamic characteristics of a viscoelastic material in much the same way as the elastic modulus represents the stressstrain characteristics of an elastic material. In other words, for a given viscoelastic material such as a bituminous concrete there is only one transfer function for a given temperature. 
Prediction of Displacements for Sinusoidal Loads

It was seen under "Concept of Transfer Euncticn" that once the trans= fer function of a system is known, it can be used to predict the output of the system for any other given input which is a function of time. After the transfer functions for the asphaltic concrete test specimens under investigation were determined, attempts were made to predict the output displacement of the specimens when subjected to a sinusoidal input of known magnitude, other than the one used to determine the transfer function. Each specimen was tested under three sinusoidal inputs at each of the thrae temperatures used previously.

From Eq. 3, the solution for the output displacement of a dynamic system with a transfer function $G(s)$ fot a sinusoidal load input of $f(t)=$ $f_{0} \sin$ th is given by

$$
\left.x^{\prime}(t)=f_{0}|G(s)| \sin \omega_{\omega} t+\theta\right)
$$

where $f_{0}=$ magnitude of the input

$\omega=$ frequency of the input

$\emptyset=$ phase angle between output and input.

In Eq. 13, $x(t)$ is a maximum when $\sin (\omega t+\emptyset)=1$, so that

$$
x(t)_{\max }=f_{0}|G(s)|
$$

Experimentally, it is convenient to $m \in a$ sure $x(t)$ max at the peak of the sinusoidal displacement output. Thus, the calculated displacement from Eq. 14 can be compared with the measured displacement for a given magnitude and frequency.

It was mentioned elsewhere that in the experimental set-up of this investigation, the input was recorded in pounds and millivoits and the output was recorded in inches and millivolts. Thus the output-input ratio can be either dimentionless or in units of inch per pound. The frequency 
spectrum and the transfer function analyses were obtained as dimensionless quantities. In applying units to $\mathrm{Eq} \cdot 14$, an experimental constant $\mathrm{K}$ needs to be introduced and it becomes

$$
x(t)_{\max }=K f_{0}|G(s)|
$$

From the sensitivity control values of the recorder, $K$ was calculated and found to be

$$
\mathrm{K}=25 \times 10^{-4} \mathrm{inch} / \text { pound }
$$

The calculated and measured values for the maximum displacement for a11 the specimens tested at $80 \mathrm{~F}$ are shown in Table 3 . In all cases the magnitude of the sinusoidal input was kept the same and only the frequency was varied. Comparison of the calculated and the measured displacement values clearly indicates the close agreement between these values in all cases. Besides proving the efficacy of the transfer function as a displacement predicting tool for viscoelastic materials, this also shows that the bituminous concrete behaves as a linear system at the levels of stress considered in the tests.

\section{Prediction of Displacements for Static Loads}

The transfer function can be used to predict the time-dependent displacements of a system subjected to a step function input, and, mathematically, a static load can be represented by a step function. For the transfer function given by Eq. 12, the solution for the displacement under a static load can be shown as

$$
x(t)=c_{1} e^{b_{1} t}+c_{2} e^{b_{2} t}+c_{3} e^{b_{3} t}+c_{4} e^{b_{4} t}+c_{5}
$$

where $C_{i}$ 's are constants independent of $t$ for the system and $b_{i}$ 's are the roots of the denominator of the transfer function which are observed 
TABLE 3

Calculated and Measured Displacements at $80^{\circ} \mathrm{F}$

\begin{tabular}{|c|c|c|c|c|c|c|c|}
\hline \multirow[t]{3}{*}{ Specimen } & \multicolumn{4}{|c|}{ Sine Load Input } & \multicolumn{3}{|c|}{ Constant Load Input } \\
\hline & \multirow[b]{2}{*}{$\begin{array}{l}f_{0} \\
\text { Ibs }\end{array}$} & \multirow[b]{2}{*}{$\begin{array}{c}\omega \\
\mathrm{rad} / \mathrm{sec}\end{array}$} & \multicolumn{2}{|l|}{$x(t)$} & \multirow[b]{2}{*}{$\begin{array}{l}\text { fo } \\
\text { lbs }\end{array}$} & \multicolumn{2}{|c|}{$x(r)$} \\
\hline & & & $\begin{array}{l}\text { calculated } \\
\text { inch }\left(\times 10^{-4}\right)\end{array}$ & $\begin{array}{l}\text { measured } \\
\text { inch }\left(\times 10^{-4}\right)\end{array}$ & & $\begin{array}{l}\text { calculated } \\
\text { inch }\left(\times 10^{-4}\right)\end{array}$ & $\begin{array}{l}\text { measured } \\
\text { inch }\left(\times 10^{-4}\right)\end{array}$ \\
\hline $2-1$ & $\begin{array}{l}5 \\
5 \\
5\end{array}$ & $\begin{array}{l}0.05 \\
0.50 \\
5.00\end{array}$ & $\begin{array}{l}2.37 \\
1.20 \\
0.58\end{array}$ & $\begin{array}{l}2.25 \\
1.25 \\
0.56\end{array}$ & $\begin{array}{l}5 \\
10 \\
15\end{array}$ & $\begin{array}{l}3.13 \\
6.26 \\
3.39\end{array}$ & $\begin{array}{r}2.50 \\
5.00 \\
10.00\end{array}$ \\
\hline$x-1$ & $\begin{array}{l}5 \\
5 \\
5\end{array}$ & $\begin{array}{l}0.05 \\
0.50 \\
5.00\end{array}$ & $\begin{array}{l}1.59 \\
0.87 \\
0.50\end{array}$ & $\begin{array}{l}1.25 \\
0.75 \\
0.50\end{array}$ & $\begin{array}{r}5 \\
10 \\
15\end{array}$ & $\begin{array}{l}2.23 \\
4.46 \\
6.69\end{array}$ & $\begin{array}{l}2.00 \\
3.75 \\
5.50\end{array}$ \\
\hline$y=1$ & $\begin{array}{l}15 \\
15 \\
15\end{array}$ & $\begin{array}{l}0.05 \\
0.50 \\
5.00\end{array}$ & $\begin{array}{l}5.32 \\
3.18 \\
1.43\end{array}$ & $\begin{array}{l}5.00 \\
3.00 \\
1.75\end{array}$ & $\begin{array}{r}5 \\
10 \\
15\end{array}$ & $\begin{array}{l}2.30 \\
4.60 \\
6.90\end{array}$ & $\begin{array}{l}2.25 \\
4.00 \\
8.75\end{array}$ \\
\hline $2-2$ & $\begin{array}{l}15 \\
15 \\
15\end{array}$ & $\begin{array}{l}0.05 \\
0.50 \\
5.00\end{array}$ & $\begin{array}{l}5.32 \\
3.18 \\
1.43\end{array}$ & $\begin{array}{l}5.00 \\
3.00 \\
1.50\end{array}$ & $\begin{array}{r}5 \\
10 \\
15\end{array}$ & $\begin{array}{l}2.30 \\
4.60 \\
6.90\end{array}$ & $\begin{array}{l}2.25 \\
4.50 \\
6.50\end{array}$ \\
\hline$x-2$ & $\begin{array}{l}15 \\
15 \\
15\end{array}$ & $\begin{array}{l}0.05 \\
0.50 \\
5.00\end{array}$ & $\begin{array}{l}4.76 \\
2.62 \\
1.50\end{array}$ & $\begin{array}{l}5.00 \\
2.50 \\
1.75\end{array}$ & $\begin{array}{r}5 \\
10 \\
15\end{array}$ & $\begin{array}{l}2.23 \\
4.46 \\
6.69\end{array}$ & $\begin{array}{l}1.25 \\
4.00 \\
9.50\end{array}$ \\
\hline$y=2$ & $\begin{array}{l}15 \\
15 \\
15\end{array}$ & $\begin{array}{l}0.05 \\
0.50 \\
5.00\end{array}$ & $\begin{array}{l}4.76 \\
2.62 \\
1.50\end{array}$ & $\begin{array}{l}4.75 \\
2.50 \\
1.50\end{array}$ & $\begin{array}{r}5 \\
10 \\
15\end{array}$ & $\begin{array}{l}2.23 \\
4.46 \\
6.69\end{array}$ & $\begin{array}{l}2.25 \\
4.00 \\
7.00\end{array}$ \\
\hline
\end{tabular}


to be negative in the case of the experimentally derived transfer functions. Two boundary conditions are applicable to Eq. 17: 1) when $t=0$, and 2) when $t=\infty$.

When $t=0$,

$$
x(t)=0
$$

that is

$$
c_{5}=c_{1}+c_{2}+c_{3}+c_{4}
$$

When $t=\infty$,

$$
x(t)=C_{5}
$$

When a constant load is applied to a viscoelastic material, the displacement approaches a constant value after a certain time depending upon the nature of the material. In the laboratory, for the bituminous concrete specimens tested, this time was observed to be in the order of a few minutes. Hence, the second boundary condition discussed above can be applied to this steady displacement value in the test, that is, Eq. 20 can be used to calculate the displacement. The limitations of using Eq. 20 are recognized in that in a test $t$ does not reach infinity and hence the measured value will be slightly lower than the calculated value.

In order to get the calculated displacement in proper units, Eq. 20 should be multiplied by the experimental constant $k$, described in the previous section so that

$$
x(t)=\mathrm{KC}_{5}
$$

where $\mathrm{K}=25 \times 10^{-4}$ inch/pound. $\mathrm{C}_{5}$ has the units of pound.

The calculated and measured values of the displacement at $80 \mathrm{~F}$ for the specimens, each under three different constant loads, are shown in Table 3 . 
Comparison of the calculated and the measured displacement values clearly indicates the close agreement between the two in almost all cases. This observation is very significant and it brings to focus the following points:

1. The mathematical theory of transfer functions is applicable to viscoelastic materials in general, and to bituminous concrete in particular.

2. The techniques developed to derive the transfer function in this investigation are sound.

3. The transfer function serves as a connecting link between the responses of the material tested under dynamic and static loads.

\section{Differential Equation from Iransfer Function}

Once the transfer function is known for a given system, the differential equation for the system behavior can be written using the Laplace inverse transform. For bituminous concrete, the transfer function was seen to be of form

$$
G(s)=\frac{A\left(s+a_{1}\right)\left(s+a_{2}\right)\left(s+a_{3}\right)}{\left(s+b_{1}\right)\left(s+b_{2}\right)\left(s+b_{3}\right)\left(s+b_{4}\right)}
$$

From definition

$$
G(s)=\frac{\dot{x}(s)}{\bar{f}(s)}
$$

From Eqs. 1 and 12 ,

$$
\frac{\bar{x}(s)}{\bar{f}(s)}=\frac{A\left(s+a_{1}\right)\left(s+a_{2}\right)\left(s+a_{3}\right)}{\left(s+b_{1}\right)\left(s+b_{2}\right)\left(s+b_{3}\right)\left(s+b_{4}\right)}
$$

Rewriting,

$\bar{x}(s)\left(s+b_{1}\right)\left(s+b_{2}\right)\left(s+b_{3}\right)\left(s+b_{4}\right)=A \bar{f}(s)\left(s+a_{1}\right)\left(s+a_{2}\right)\left(s+a_{3}\right)$

Multiplying and rearranging the terms,

$$
\bar{x}(s)\left[s^{4}+B_{1} s^{3}+B_{2} s^{2}+B_{3} s+B_{4}\right]=A \bar{f}(s)\left[s^{3}+B_{5} s^{2}+B_{6} s+B_{7}\right]
$$




$$
\text { where } \begin{aligned}
B_{1} & =b_{1}+b_{2}+b_{3}+b_{4} \\
B_{2} & =b_{1} b_{2}+b_{2} b_{3}+b_{3} b_{4}+b_{4} b_{1}+b_{4} b_{2}+b_{3} b_{1} \\
B_{3} & =b_{1} b_{2} b_{3}+b_{2} b_{3} b_{4}+b_{3} b_{4} b_{1}+b_{4} b_{12} b_{2} \\
B_{4} & =b_{1} b_{2} b_{3} b_{4} \\
B_{5} & =a_{1}+a_{2}+a_{3} \\
B_{6} & =a_{1} a_{2}+a_{2} a_{3}+a_{3} a_{1} \\
B_{7} & =a_{1} a_{2} a_{3}
\end{aligned}
$$

Rewriting Eq. 24 ,

$$
\begin{aligned}
& s^{4 \bar{x}}(s)+B_{1} s^{3} \bar{x}(s)+B_{2} s^{2} \bar{x}(s)+B_{3} s \bar{x}(s)+B_{4} \bar{x}(s) \\
& =A\left[s^{3} \bar{f}(s)+B_{5} s^{2} \bar{f}(s)+B_{6} s \bar{f}(s)+B_{7} \bar{f}(s)\right]
\end{aligned}
$$

Applying the Laplace inverse transform,

$$
\begin{aligned}
\frac{d^{4} x(t)}{d t^{4}} & +B_{1} \frac{d^{3} x(t)}{d t^{3}}+B_{2} \frac{d^{2} x(t)}{d t^{2}}+B_{3} \frac{d x(t)}{d t}+B_{4} x(t) \\
& =A\left[\frac{d^{3} f(t)}{d t^{3}}+B_{5} \frac{d^{2} f(t)}{d t^{2}}+B_{6} \frac{d f(t)}{d t}+B_{7} f(t)\right]
\end{aligned}
$$

Eq. 33 is a fourth order linear differential equation with constant coefficients which describes the dynamics of the bituminous concrete. The input (force) and the output (displacement) are the two variables in the equation which are functions if time. The constants $B_{i}$ 's are easily determined from the roots of the denominator, $b_{i}$ 's, and from those of the numerator, $a_{i}$ 's, of the transfer function, using Eqs. 25 through 31.

It is of significance to note here that these roots of the differential equation are obtained as the corner frequencies directly from the frequency spectrum for the material under test, and no assumption whatsoever has been made in deriving the equation. 
Based on the results and within the limitations of this investigation, the following conclusions are enumerated:

1. The viscoelastic or time-dependent characteristics of an asphaltic concrete can be represented by a transfer function $G(s)$ which is a function of the complex variable $s$. The transfer function is unique for the material at a given temperature. It is possible to obtain this function experimentally from a series of sinusoidal load tests on the material.

2. The transfer function for an asphaltic concrete is of the form

$$
G(s)=\frac{A\left(s+a_{1}\right)\left(s+a_{2}\right)\left(s+a_{3}\right)}{\left(s+b_{1}\right)\left(s+b_{2}\right)\left(s+b_{3}\right)\left(s+b_{4}\right)}
$$

where $A$ is a constant, and $a_{i}$ 's and $b_{i}$ "s are roots of the numerator and denominator, respectively.

3. The rcots of the denominator of $G(s)$, namely $b_{1}, b_{2}, b_{3}$ and $b_{4}$, are negative, real and distinct, thus indicating that bituminous concrete behaves as an overdamped system.

4. Parameters obtained in the transfer function for bituminous concrete are believed to be better indicators of material performance than those commonly used, such as, Young 's modulus, Poisson"s ratio, etc. which change with rate and time of loading.

5. Temperature is the one single factor which has the greatest effect on the transfer function of asphaltic concrete. Increase in temperature increases the value of the constant $A$ in the transfer function equation.

6. The transfer function is a powerful tool useful in predicting the displacement of asphaltic concrete under an applied load, dynamic or static. By treating the static load as a step function of time, the resulting displacement can be calculated by means of the tratsfer function derived experimentally from the dynamic test. The excellent agreement between the calculated 
and measured values of the displacement in this investigation validates the concept that the transfer function represents a material property which is inclependent of the type of load input.

7. Through the use of the transfer function and without assuming any spring-dashpot model, it is possible to represent the time-dependent behavior of asphaltic concrete by a fourth order linear differential equation with constant coefficients. The coefficients can be computed from the routs of the denominator and numerator of the transfer function. 


\section{ACKNOWLEDGMENTS}

The authors wish to acknowledge the assistance of the Bureau of Public Roads, U. S. Department of Commerce, who supported the investigation with the Indiana State Highway Commission.

Laboratory testing and experimental techniques were carried out in the Bituminous Materials Laboratory of the Joint Highway Research Project at Purdue University, Lafayette, Indiana. 


\section{BIBLIOGRA PHY}

1. Lee, E. H., "Stress Analysis in Viscoelastic Bodies", Quarterly of Applied Mathematics, July 1955.

2. Biot, M. A., "Dynamics of Viscoelastic Anisotropic Media," Proceedings, Fourth Midwestern Conference on Solid Mechanics, September 1955.

3. Biot, M. A., "Theory of Stress-Strain Relations in Anisotropic Viscoelasticity and Relaxation Phenomena, "Journal of Applied Physics, Vo1. 25, No. 11, November 1954.

4. Lee, E. H., "Viscoelastic Stress Analysis," Structural Mechanics, proceedings, First Symposium on Naval Structural Mechanics, Pergamon Press, New York, 1960.

5. Lee, E. H., and Rogers, T. G., "Solution of Viscoelastic Analysis Problems using Measured Creep or Relaxation Functions", Journal of Applied Mechanics, Vo1. 30, No. 1, March 1963.

6. Pister, K. S., and Monismith, C. L., "Analys is of Viscoelastic Flexible Pavements," Flexible Pavement Design Studies 1960, Highway Research Bulletin 269, 1960.

7. Pister, K. S., "Viscoelastic Plate on a Viscoelastic Foundation," Journal of the Engineering Mechanics Division, Proceedings, A. S. C. E., Vol. 87, No. EM1, February 1961.

8. Pister, K. S., and Williams, M. L., "Bending of Plates on a Viscoelastic Foundation," Journal of the Engineering Mechanics Division, Proceedings, A. S. C. E., Vo1. 86, No. EM5, October 1960.

9. Reissner, E., "A Note on Deflections of Plates on Viscoelastic Foundation," Transactions, A.S.M.E., Vol. 25, No. 1, March 1958.

10. Hoskin, B. C., and Lee, E. H., "Flexible Surfaces on Viscoelastic Subgrades," Journal of the Engineering Mechanics Division, Proceedings, A.S.C.E., Vo1. 85, No. EM 4, October 1959.

11. Harr, M. E., "Influence of Vehicle Speed on Pavement Deflection," Proceedings, Highway Research Board, Vol. 41, 1962.

12. Wood, L. E., and Goetz, W. H., "Rheological Characteristics of a Sand-Asphalt Mixture," Proceedings, AAPT, Vol. 28, 1959.

13. Secor, K. E., and Monismith, C. L., "Analysis of Triaxial Test Data on Asphalt Concrete using Viscoelastic Principles," Proceedings, Highway Research Board, Vo1. 40, 1961.

14. Kuhn, S. H., and Rigden, P. J., "Measurement of Viscoelastic Properties of Bitumens under Dynamic Loading," Proceedings, Highway Research Board, Vol. 38, 1959. 
15. Papazian, H. S., "The Response of Linear Viscoelastic Materials in the Frequency Domain with Emphasis on Asphaltic Concrete," Proceedings, International Conference on the Structural Design of Asphalt Pavements, University of Michigan, 1962.

16. Pagen, C.A., "Rheological Response of Bituminous Concrete," Bituminous Materials and Mixes, Highway Research Record No. 67, Highway Research Board, 1965.

17. Kallas, B. F., and Riley, J.C., "Mechanical Properties of Asphalt Pavement Materials," Proceedings, Second International Conference on the Structural Design of Asphalt Pavements, University of Michigan, 1967.

18. Truxal, J.C., Control System Synthesis, McGraw-Hill Book Co., 1955.

19. Nixon, F.E., Principles of Automatic Controls, Prentice Hall, Inc., 1960 .

20. Goldberg, J.H., Automatic Controls: Principles of Systems Dynamics, Allyn Bacon, Boston, 1964.

21. Tsien, H.S., Engineering Cybernetics, McGraw-Hill Book Co., 1954.

22. Etkin, B., Dynamics of Flight, John Wiley E Sons, 1959.

23. Crafton, P.A., Shock and Vibration in Linear systems, Harper E Brothers, N. Y., 1961 .

24. Busching, H. W., Goetz, W. H., and Harr, M. E., "Stress-Deformation Behavior of Anisotropic Bituminous Mixtures," Proceedings, AAPT Vol. 36, 1967.

25. Lister, N.W., and Jones, R., "The Behavior of Flexible Pavements under Moving Wheel Loads," Proceedings, Second International Conference on the Structural Design of Asphalt Pavements, University of Michigan, 1967 .

26. Swami, S. A., "The Response of Bituminous Mixtures to Dynamic and Static Loads Using Transfer Functions," Ph. D. Thesis, submitted to Purdue University, Lafayette, Indiana, Jan. 1969. 
. 
